\title{
Speech-language pathology Student Participation in Verbal Reflective Practice Groups: perceptions of development, value and group condition differences.
}

\author{
Gina D. Tillard \\ University of Canterbury, gina.tillard@icloud.com \\ Kate Cook \\ University of Canterbury, kate.cook@canterbury.ac.nz \\ Daniel Gerhard \\ University of Canterbury, daniel.gerhard@canterbury.ac.nz
}

See next page for additional authors

DOI: doi.org/10.30707/TLCSD2.2Tillard

Follow this and additional works at: https://ir.library.illinoisstate.edu/tlcsd

Part of the Scholarship of Teaching and Learning Commons, and the Speech Pathology and Audiology

\section{Commons}

\section{Recommended Citation}

Tillard, Gina D.; Cook, Kate; Gerhard, Daniel; Keast, Lydia; and McAuliffe, Megan (2018) "Speech-language pathology Student Participation in Verbal Reflective Practice Groups: perceptions of development, value and group condition differences.," Teaching and Learning in Communication Sciences \& Disorders: Vol. 2: Iss. 2, Article 5.

DOI: doi.org/10.30707/TLCSD2.2Tillard

Available at: https://ir.library.illinoisstate.edu/tlcsd/vol2/iss2/5

This Scholarship of Teaching and Learning Research is brought to you for free and open access by ISU ReD: Research and eData. It has been accepted for inclusion in Teaching and Learning in Communication Sciences \& Disorders by an authorized editor of ISU ReD: Research and eData. For more information, please contact ISUReD@ilstu.edu. 


\title{
Speech-language pathology Student Participation in Verbal Reflective Practice Groups: perceptions of development, value and group condition differences.
}

\begin{abstract}
The aim of this study was to determine whether significant differences in perceptions of reflective practice were present across two groups of students engaged in standard practice and experimental group conditions. Twenty-seven undergraduate speech-language pathology students participated in the study. A two-condition, non-randomised, pre-test post-test design was employed with two groups (a standard practice condition and an experimental practice condition, utilizing structured activities and prompts). Participants took part in weekly reflective practice groups over a six week period, in which discussion centered on students' clinical experiences. Pre and post intervention, the students completed a questionnaire designed to examine perceptions of reflective practice in the differing conditions. Overall, students' perceptions of reflective practice as a learning tool were positive. In contrast to our hypotheses, students' perceptions of reflective practice did not change significantly over time. Furthermore, there was no differences in perceptions in the experimental practice (i.e., structured activities and prompts) group as compared to the standard practice group. Students perceive verbal reflective practice as a positive learning experience regardless of the discussion format utilized. Implications for clinical teaching are discussed.
\end{abstract}

\section{Keywords}

reflective practce, clinical education, speech pathology

\section{Cover Page Footnote}

Acknowledgements The authors would like to thank all speech-language pathology students who participated in this study during the 2015 academic year.

\section{Authors}

Gina D. Tillard, Kate Cook, Daniel Gerhard, Lydia Keast, and Megan McAuliffe 


\section{Introduction}

Reflective practice in clinical education. Reflective practice is defined as "...the means by which learners can make sense of and integrate new learning into existing knowledge" (McAllister \& Lincoln, 2004, p. 125). Globally, as a part of the clinical education process, students and practitioners in health-related professions regularly engage in reflective practice activities. Professions such as medicine (Mamede \& Schmidt, 2004), nursing (Dubé \& Ducharme, 2014; Johns, 1995; Teekman, 2000), occupational therapy (Kinsella, 2001; Wainwright, Shepard, Harman \& Stephens, 2010), physiotherapy (Clouder, 2000; Dunfee, Rindflesch, Driscoll, Hollman \& Plack, 2008; Plack, Driscoll, Blissett, McKenna \& Plack, 2005) and speech-language pathology (Hill, Davidson \& Theodoros, 2012) have all used reflective practice as part of the education process for students and practitioners. Reflective practice in clinical education serves to incorporate the contextual aspects of an individual's experience, and develop reasoning skills, improved decision making and professional autonomy (Kinsella, Caty, Ng \& Jenkins, 2012; McVey \& Jones, 2012; Wainwright et al., 2010; McAllister \& Lincoln, 2004; Wong, Kember, Chung, \& Yan, 1995). Reflective practice is also intended to assist students in synthesising classroom knowledge with their clinical practice (Dunfee et al., 2008).

A clinical educator's role is to assist learners to competently navigate clinical situations. Reflective practice may assist in this process (Wong et al., 1995). When working in the realm of clinical education it is also important to understand the value of specific reflective practice activities for the end user (the students). In particular, a focus on perception of value and learning taken from reflective practice in a group environment can serve to inform clinical education programs (Knowles, Holton, \& Swanston, 2005). Furthermore, approaches that enhance the value of reflective practice have the potential to result in improved engagement in the process and foster students' skill development (Hill et al., 2012; Knowles et al., 2005).

Methods of reflective practice utilised in speech-language pathology. The most common methods of reflective practice in speech-language pathology (SLP) are written reflective practice and verbal reflective practice groups (Caty, Kinsella, \& Doyle, 2015). Specific methods of undertaking written reflective practice include reflective journaling or log (Freeman, 2001; Hill et al., 2012), written summaries (Schaub-de Jong, Cohen, Schotanus, Dekker, \& Verkerk, 2009), and guided reflections (Kember, 1999). Verbal reflective practice approaches include group discussions with peers (Baxter \& Gray, 2001), mentors (Higgs \& McAllister, 2007) and supervisors (Geller \& Foley, 2009). The use of small group discussion is a common approach (Caty et al., 2015), and the focus of this study.

Facilitation of discussion is a key issue in the small group context. Various materials have been used to facilitate discussion in the small group context. These include review of case studies (Johnston \& Banks, 2000), analysis of details of clinical practice (Fronek, Kendall, Ungerer, Malt, Eugarde \& Geraghty, 2009), discussion of feedback on performance (Bruce, Parker \& Herbert, 2001), and shared stories (O'Halloran, Hersh, Laplante-Levesque \& Worrall, 2010). It is accepted that both written and verbal modalities could allow for reflective practice opportunities within a group environment. 
Verbal reflective practice groups. Verbal reflective practice groups (also identified as action learning groups) serve to assist reflective practice through the sharing of self-evaluations, knowledge, perspectives and experiences with group members, while also providing peer support (Graham, 1995; Haddock, 1997). In these small groups, and with a facilitator present, clinical questions, incidents or topics are discussed (Dubé \& Ducharme, 2015; Haddock, 1997; Heidari \& Galvin, 2002). The opportunity to deeply examine experiences is believed to stimulate curiosity and effective learning in a safe environment (Heidari \& Galvin, 2002; McVey \& Jones, 2012; McAllister \& Lincoln, 2004).

There is potential for considerable student learning and reflective development from engagement in verbal reflective practice groups. Students own beliefs, values and assumptions may be challenged more readily through the presentation of alternate perspectives of other group members when compared to individual reflective practice formats such as verbal selfreflection or written reflection (McDougall \& Comfort, 2013). In addition, analysis of behaviours or patterns within a group is a collaborative and cooperative endeavour, which may also result in increased learning (Osterman \& Kottkamp, 1993).

Adding structure to reflective practice. Despite the regular use of structure in written reflective practice studies (Hill et al., 2012; Kember, 1999; Plack et al., 2005) there continues to be disagreement surrounding the benefit of structure on the development of reflective practice skills. It has been suggested that structure may inhibit creative thinking (Johns, 2013) . Furthermore, concerns have been raised that structure could transform reflection into a methodical process with "checklists that students work through in a mechanical fashion without regard to their own uncertainties, questions and meanings" (Boud \& Walker, 1998, p. 193). In contrast, Franks, Watts, and Fabricus (1994) support the implementation of structure in reflective practice groups to provide boundaries for the group discussion including meeting times, group member roles and responsibilities and discussion topics. This can reduce participant anxiety and increase safety, which in turn allows participants to openly reflect on and share their behaviours, beliefs, and understandings of an experience or topic (Franks et al., 1994, Johns, 2004, Stock Whittaker, 1985). In addition, the use of structured activities that vary from one occasion to the next may also serve to reduce the routine nature of reflective practice, and reduce the negative feelings or "non-learning" that may be associated with compulsory reflective practice reported by many students (Gray, 2007).

Seeking student perceptions of learning and reflective practice. Past studies investigating student perceptions of reflective practice have been completed using questionnaires, selfevaluations, and focus groups (Harris, 2005; Lim \& Low, 2008a; 2008b; Ng, Bartlett, \& Lucy, 2012; Roche \& Coote 2008). Students have reported that reflective practice provides positive additions to their learning including: a memory aid, a way to gain feedback, a dedicated time to ensure they are reflecting, increased self-awareness and self-care, complementing evidenced based practice; enjoyment of group discussions, and developing their professional identity (Lim \& Low, 2008a; 2008b; Ng et al., 2012; Roche \& Coote, 2008). However, there are also negatives associated with the reflective practice process, such as the time consuming nature of the task and a lack of knowledge of reflective practice processes (Harris, 2005; Lim \& Low, 2008a). 
The use of reflective practice groups has also been viewed positively. Nursing and health sciences students viewed group discussion as a worthwhile experience that helped link theory and practice (Lim \& Low, 2008b; McGrath \& Higgins, 2006; Schaub de Jong et al., 2009). Students have also reported that group meetings developed personal and professional behaviours through the process of questioning their own values, beliefs and biases (McKinlay \& Ross, 2008; Schaub de Jong et al., 2009). On this basis, it appears likely that SLP students would also find engagement in reflective practice groups a positive learning experience. However, it is unknown whether there are differing student perceptions towards specific aspects of reflection, or the impact of time on student perception of reflective learning. In addition, it is unclear whether a structured discussion format (including activities or guiding questions) or unstructured discussion impact student perceptions of reflective practice as a learning tool.

In summary, there is widespread support for the use of group discussion in reflective practice (Caty et al., 2015). The interaction with peers allows for the exchange and comparison of beliefs and behaviours, perspectives and opinions, and creates a new sense of personal awareness for those involved. While past studies have begun to examine the impact of SLP student reflective practice abilities through assessment (Hill et al., 2012, Cook, Tillard, Wyles, Gerhard, Ormond, \& McAuliffe, 2017)) and group discussions (Baxter \& Gray, 2001) further investigation into SLP student perceptions of reflective practice and the change of perception over time is warranted. Therefore, this study asked:

1. How do SLP students perceive reflective practice as a learning tool?

2. Do SLP students completing verbal reflective practice groups perceive development in their reflective practice skills over time?

3. Do SLP students in the experimental condition (structured activities) perceive they are developing greater reflective practice skills over time compared to students in the standard practice condition?

\section{Method}

This study received ethical approval from the Educational Human Ethics Committee of the University. All participants provided written consent to participate.

Context of the study. This study was conducted as part of a clinical program for undergraduate SLP students. In New Zealand, which takes a similar educational approach to Australia and the UK, students have two degree options to become practicing SLPs - either through a four year undergraduate degree or a two year Master degree. They current study focused on students in the undergraduate degree. Typically, these students complete six clinical placements and log a total of at least 350 hours of clinical practice. The students were in their fourth clinical placement experience (of six across the course of the degree). Participation in reflective practice groups was standard practice and mandatory in order for undergraduate students to complete the clinical component of the degree. Students were undertaking various clinical placements working with children or adults up to four afternoons per week for the duration of data collection. 
Participants. A total of 27 individuals ( 25 female, 2 males) participated in the current study. Ages of participants ranged from 19.6 years to 52 years at the time of the study. Mean age was 22.9 years.

Procedures. The study was conducted in the context of reflective practice groups for SLP students. The groups aimed to engage students in reflective discussions integrating previous experiences and knowledge to assist with problem solving case management and team based queries as they arise. All students were participating in reflective practice groups for the first time. A two-group, non-randomised, pre-test post-test design was employed with six groups (three who engaged in experimental practice, three who did not). The reflective practice groups ran between 45 minutes to one hour per meeting for a period of 12 weeks. The groups comprised of two phases - an initial phase of group dynamics development and an intervention phase. Groups were facilitated by Clinical Educators (CEs) trained to facilitate the groups in accordance with the protocols of the study. A CE was present in all reflective practice groups and facilitated the group within a clearly defined and limited role.

Details of the structure of the verbal reflective practice groups attended by the students are provided in Table 1.

Table 1: Setup and structure of verbal reflective practice groups

Group allocation:

Three groups of five students were created with one CE per group. Both group and clinical educator were randomly assigned. Groups were then reviewed by the researcher to ensure equitable student ability were established using clinical competency outcome scores.

Clinical Educator (CE) training:

1. Education was provided regarding Brookshire's (2003) format of session organization;

2. Written and video guidelines were distributed.

3. A 1 hour training session was completed with the researcher to discuss facilitation techniques, questions, and potential difficulties.

4. CEs were trained to facilitate the reflective practice group only by prompting or asking questions in order to generate discussion.

5. CEs were advised that if students had no contributions to make following a prompt, they may contribute a personal experience with the purpose of igniting student discussion.

Experimental practice only:

CEs in the experimental practice group received an extra hour of training targeted towards understanding how to use the structured activities and accompanying questions.

Phase 1 Development of group dynamics: Session 1 - 6:

Group discussion centred on articles related to clinical issues. 
Phase 2 Intervention: Sessions $7-12$

Standard practice group:

1. 50-minute group discussion that centred on the student's clinical experiences.

2. Groups were run according to Brookshire's (2003) session organization format in order to ensure this time period and consistency of group execution. Discussions were facilitated by students and with support from a CE.

3. Discussions integrated previous experiences and knowledge in an effort to assist with problem solving case management and team based queries as they arose.

Experimental practice group:

1. 50-minute group discussion that centred on the student's clinical experiences.

2. Groups were run according to Brookshire's (2003) session organization format in order to ensure this time period, and consistency of group execution. Structured activities were used to support and facilitate discussion.

3. Six activities were used, with the intent to prompt reflective statements from students, enhance discussion, and improve student perceptions of reflective practice within the group setting.

4. The structured activities were accompanied by questions developed from prompts for reflection (McAllister \& Lincoln, 2004), specifically structured to increase and enhance the breadth of reflective statements, as defined by Plack et al., (2005).

5. Each activity involved student turn-taking following which a student would read out a question to the group.

Instrument. A Visual Analogue Scale (VAS) questionnaire was distributed via Qualtrics software (Qualtrics, 2017) pre- and post- the intervention phase. The aim of the questionnaires was to gauge group perceptions of reflective practice, how this changed over the course of six weeks, and specifically, the impact of structured activities on this change. As no validated questionnaire existed prior to the study, the researchers developed a fit-for-purpose questionnaire by reviewing key terminology and behavioural descriptors from the reasoning, learning, life-long learning, and reflective practice competencies of a valid and reliable competency assessment (COMPASS ${ }^{\circledR}$ McAllister, Lincoln, Ferguson, \& McAllister, 2013). Next, breadth of reflection elements from a valid and reliable measure for written reflective practice (Plack et al., 2005) and findings of past studies investigating student perceptions of reflective practice (Harris, 2005; Lim \& Low, 2008a; 2008b; Ng et al., 2012; Roche \& Coote, 2008) were reviewed and summarized. Finally a statement was developed for key terminology found in all resources and was agreed on by all researchers for inclusion in the questionnaire (Appendix). The statements in the questionnaire were reviewed by the researchers and streamlined to begin with the carrier phrase 'I am able to...' A VAS was chosen to allow the participants make judgements on their perceived level of development of reflective practice using the keywords "all of the time" or "none of the time".

The questionnaire was piloted by a cohort of students not involved in the study. The students were asked to complete the questionnaire and provide feedback on comprehensibility of the statements, relevance of each statement to reflective practice, and time taken to complete the questionnaire. Following this, minor revisions were made such as changes in wording and inclusion of the term "reflect" in each question. The final questionnaire contained 24 questions relating to reflective practice (see Table 2). The questionnaire was presented in an online 
format, which allowed for standardization of line length, increased speed of access to data, and accuracy of scoring. The questionnaire was also formatted to require responses from all questions in order to progress onto the following question: therefore, participants were unable to submit the questionnaire without responding to all questions. In order to ensure high response rate, time was set aside within the one hour allocated for reflective practice groups for students complete the questionnaire via a URL link. Any students that had not completed the pre-post intervention questionnaires within 24 hours of the reflective practice groups were sent one reminder email. Following this, if the questionnaire was not completed, their data was not collected for the specific time point.

\section{Data analysis}

The output from both the pre- and post- intervention questionnaires were generated using Qualtrics software (Qualtrics, 2017). The Qualtrics survey software automatically measured the distance of each response using the automated output features from Qualtrics software and converted this to ratio level data from 1-10, where 1 indicated the most negative scale point and a higher number was more positive. This allowed individual participant means and statistical analysis to be calculated (Qualtrics, 2017). The researchers determined that a ratio of six or more was interpreted as a positive response to the statements.

Statistical analysis. Descriptive statistics were used to report the average questionnaire scores for each participant. A linear mixed effects model was fit separately for each individual question using the R package "Ime4" (Bates, Maechler, Bolker, \& Walker, 2015). The purpose was to: (1) compare standard practice and experimental practice conditions, (2) investigate their effect over time (pre- vs. post-intervention), and (3) explain the variability in scores between and within participants reflecting the repeated measurement design of the study. Simultaneous confidence intervals were calculated, controlling the familywise error rate at a global confidence level of $(1-\alpha)=0.95$. The empirical covariance between multiple marginal models was estimated according to Ritz, Laursen, and Damsgaard (2016), allowing for simultaneous inference for multiple contrasts (e.g., averaging coefficients of multiple models).

\section{Results}

Twenty-four participants (88\%) completed the questionnaire both pre- and post- intervention.

Student perceptions of reflective practice as a learning tool. Figure 1 presents the observed and expected participant response scores for both the standard practice and experimental practice conditions for reflective practice groups pre- and post-intervention. The overall average estimates are 7.21- 7.69 over time for the standard practice group and $6.67-7.72$ over time for the experimental practice group (Table 2). The observed and expected participant responses (Figure 1) and overall average estimates (Table 2) indicate that the majority of participants perceived reflective practice as a learning tool that aided their development with average estimates of 6 or more in both conditions. 


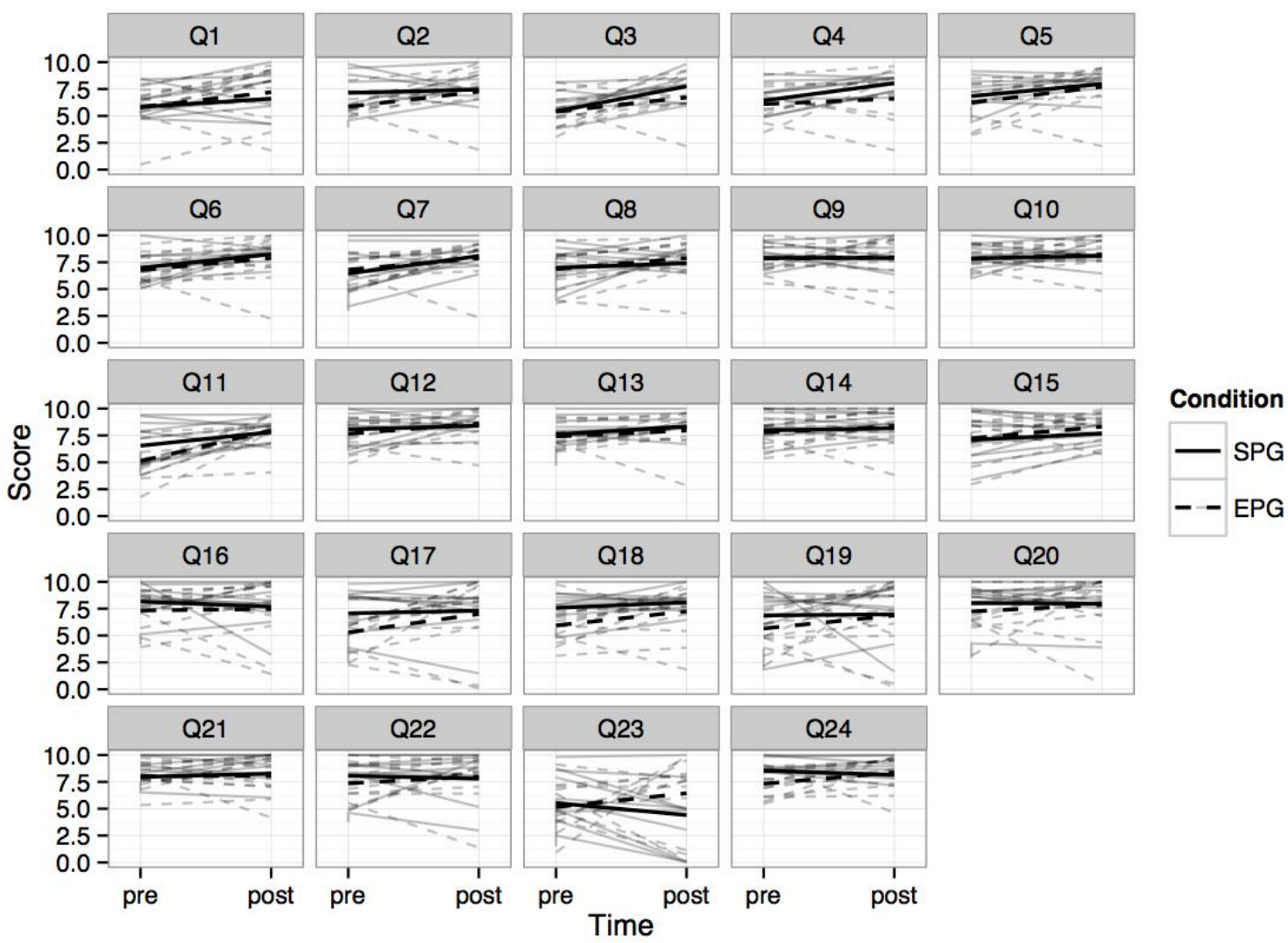

Figure 1. Expected participant score representing perception of reflective practice pre and post intervention (Time) for both the standard practice group (SPG) and experimental practice group (EPG). The grey lines represent individual participant responses pre- and postintervention.

Student perception of reflective practice development over time. To evaluate the effect of time on participant perception of reflective practice development for both groups we fitted 26 linear mixed-effects models (Bates et al., 2015), a separate model for each question, estimating the expected population scores while taking the repeated measurements structure for each participant into account. Simultaneous inference for each marginal model and for averaged coefficients is provided for the full set of the 26 models (Ritz et al., 2016). The estimated coefficients are shown in Table 2, together with their corresponding simultaneous confidence intervals. The change in this effect over time from pre- to post-intervention is denoted as a change in slope parameters, interpreted as the change in expected score difference of experimental versus standard practice groups associated with an increase of one unit in time. Output of the final statistical model is shown in Table 2. As can be seen, both groups demonstrate change over time for almost all questions (indicating more or less perception of development over time), however; there is no significant effect of time regardless of condition. 
Table 2. Expected differences in student VAS Questionnaire scores (0-10) comparing the standard practice with the experimental practice condition pre-intervention and the impact of time on these scores (intervention effect). Coefficient estimates (simultaneous $(1-\alpha)=0.95$ confidence limits)

\begin{tabular}{|c|c|c|c|c|c|}
\hline Q\# & Question & $\begin{array}{l}\text { Intercept } \\
\text { (expected score } \\
\text { for standard } \\
\text { practice) }\end{array}$ & $\begin{array}{l}\text { Experimental } \\
\text { practice effect }\end{array}$ & $\begin{array}{l}\text { Intervention } \\
\text { effect for } \\
\text { standard } \\
\text { practice }\end{array}$ & $\begin{array}{l}\text { Change in } \\
\text { intervention } \\
\text { effect for } \\
\text { experimental } \\
\text { practice } \\
\end{array}$ \\
\hline 1 & $\begin{array}{l}\text { I am able to } \\
\text { information from } \\
\text { sources to make } \\
\text { when engagerent } \\
\text { practice. }\end{array}$ & $\begin{array}{c}5.83 \\
(5.18 ; 7.48)\end{array}$ & $\begin{array}{c}0.00 \\
(-2.36 ; 2.35)\end{array}$ & $\begin{array}{c}0.76 \\
(-1.23 ; 2.76)\end{array}$ & $\begin{array}{c}0.61 \\
(-2.08 ; 3.31)\end{array}$ \\
\hline 2 & $\begin{array}{l}\text { I am able to apply new insights } \\
\text { and knowledge to clinical } \\
\text { situations. }\end{array}$ & $\begin{array}{c}7.14 \\
(5.58 ; 8.71)\end{array}$ & $\begin{array}{c}-1.29 \\
(-3.55 ; 0.98)\end{array}$ & $\begin{array}{c}0.30 \\
(-1.93 ; 2.54)\end{array}$ & $\begin{array}{c}1.10 \\
(-1.98 ; 4.17)\end{array}$ \\
\hline 3 & $\begin{array}{l}\text { I am able to link theory to } \\
\text { practice in order to better } \\
\text { understand clinical situations. }\end{array}$ & $\begin{array}{c}5.43 \\
(3.98 ; 6.88)\end{array}$ & $\begin{array}{c}-0.04 \\
(-2.20 ; 2.11)\end{array}$ & $\begin{array}{c}2.31 \\
(-0.32 ; 4.94)\end{array}$ & $\begin{array}{c}-0.99 \\
(-4.60 ; 2.62)\end{array}$ \\
\hline 4 & $\begin{array}{l}\text { I am able to effectively explain } \\
\text { my reasoning processes and } \\
\text { thinking. }\end{array}$ & $\begin{array}{c}6.42 \\
(4.76 ; 8.08)\end{array}$ & $\begin{array}{c}-0.32 \\
(-2.77 ; 2.12)\end{array}$ & $\begin{array}{c}1.62 \\
(-0.65 ; 3.88)\end{array}$ & $\begin{array}{c}-1.11 \\
(-4.22 ; 1.99)\end{array}$ \\
\hline 5 & $\begin{array}{l}\text { I am able to identify what I } \\
\text { need to learn to make a } \\
\text { decision about a client/clinical } \\
\text { situation. }\end{array}$ & $\begin{array}{c}6.84 \\
(5.33 ; 8.35)\end{array}$ & $\begin{array}{c}-0.61 \\
(-2.87 ; 1.66)\end{array}$ & $\begin{array}{c}1.14 \\
(-0.93 ; 3.21)\end{array}$ & $\begin{array}{c}0.36 \\
(-2.55 ; 3.26)\end{array}$ \\
\hline 6 & $\begin{array}{l}\text { I am able to look at multiple } \\
\text { points of view in clinical } \\
\text { situations. }\end{array}$ & $\begin{array}{c}6.99 \\
(5.68 ; 8.29)\end{array}$ & $\begin{array}{c}-0.21 \\
(-2.11 ; 1.68)\end{array}$ & $\begin{array}{c}1.26 \\
(-0.69 ; 3.22)\end{array}$ & $\begin{array}{c}-0.15 \\
(-2.77 ; 2.48)\end{array}$ \\
\hline 7 & $\begin{array}{l}\text { I am able to reflect on my } \\
\text { clinical performance in } \\
\text { relation to my clinical practice } \\
\text { or COMPASS } \\
\text { competencies. }\end{array}$ & $\begin{array}{c}6.45 \\
(4.75 ; 8.16)\end{array}$ & $\begin{array}{c}0.35 \\
(-2.09 ; 2.78)\end{array}$ & $\begin{array}{c}1.62 \\
(-0.49 ; 3.74)\end{array}$ & $\begin{array}{c}-0.55 \\
(-3.54 ; 2.44)\end{array}$ \\
\hline 8 & $\begin{array}{l}\text { I am able to identify strengths } \\
\text { in my clinical skills. }\end{array}$ & $\begin{array}{c}6.99 \\
(5.33 ; 8.64)\end{array}$ & $\begin{array}{c}-0.14 \\
(-2.51 ; 2.23) \\
\end{array}$ & $\begin{array}{c}0.42 \\
(-1.52 ; 2.36) \\
\end{array}$ & $\begin{array}{c}0.62 \\
(-2.12 ; 3.35) \\
\end{array}$ \\
\hline 9 & $\begin{array}{l}\text { I am able } \text { to identify } \\
\text { weaknesses in my clinical } \\
\text { skills. }\end{array}$ & $\begin{array}{c}7.91 \\
(6.59 ; 9.23)\end{array}$ & $\begin{array}{c}-0.08 \\
(-2.00 ; 1.85)\end{array}$ & $\begin{array}{c}-0.02 \\
(-1.76 ; 1.72)\end{array}$ & $\begin{array}{c}0.13 \\
(-2.32 ; 2.59)\end{array}$ \\
\hline 10 & $\begin{array}{l}\text { I am able to use constructive } \\
\text { feedback to improve my } \\
\text { performance in clinic. }\end{array}$ & $\begin{array}{c}7.85 \\
(6.85 ; 8.86)\end{array}$ & $\begin{array}{c}-0.01 \\
(-1.48 ; 1.45)\end{array}$ & $\begin{array}{c}0.23 \\
(-1.13 ; 1.58)\end{array}$ & $\begin{array}{c}0.13 \\
(-1.81 ; 2.08)\end{array}$ \\
\hline 11 & $\begin{array}{l}\text { I am able to reflect on clinical } \\
\text { experiences within the session. }\end{array}$ & $\begin{array}{c}6.55 \\
(5.09 ; 8.00)\end{array}$ & $\begin{array}{c}-1.43 \\
(-3.55 ; 0.69)\end{array}$ & $\begin{array}{c}1.27 \\
(-0.56 ; 3.10)\end{array}$ & $\begin{array}{c}1.59 \\
(-0.99 ; 4.18)\end{array}$ \\
\hline 12 & $\begin{array}{l}\text { I am able to reflect on clinical } \\
\text { experiences following the } \\
\text { session. }\end{array}$ & $\begin{array}{c}8.06 \\
(6.68 ; 9.43)\end{array}$ & $\begin{array}{c}-0.41 \\
(-2.41 ; 1.60)\end{array}$ & $\begin{array}{c}0.34 \\
(-1.29 ; 1.97)\end{array}$ & $\begin{array}{c}0.60 \\
(-1.73 ; 2.93)\end{array}$ \\
\hline 13 & $\begin{array}{l}\text { I am able to reflect on clinical } \\
\text { experiences to plan for what I }\end{array}$ & $\begin{array}{c}7.59 \\
(6.44 ; 8.74)\end{array}$ & $\begin{array}{c}-0.18 \\
(-1.83 ; 1.46)\end{array}$ & $\begin{array}{c}0.75 \\
(-0.79 ; 2.30)\end{array}$ & $\begin{array}{c}-0.21 \\
(-2.35 ; 1.94)\end{array}$ \\
\hline
\end{tabular}




\begin{tabular}{|c|c|c|c|c|c|}
\hline & $\begin{array}{l}\text { need to do differently in future } \\
\text { clinical sessions. }\end{array}$ & & & & \\
\hline 14 & $\begin{array}{l}\text { I am able to reflect on a session } \\
\text { and describe what has } \\
\text { happened. }\end{array}$ & $\begin{array}{c}7.97 \\
(6.62 ; 9.31)\end{array}$ & $\begin{array}{c}-0.20 \\
(-2.12 ; 1.72)\end{array}$ & $\begin{array}{c}0.20 \\
(-1.23 ; 1.62)\end{array}$ & $\begin{array}{c}0.38 \\
(-1.59 ; 2.35)\end{array}$ \\
\hline 15 & $\begin{array}{l}\text { I am able to reflect on my } \\
\text { clinical practice without } \\
\text { feeling anxious. }\end{array}$ & $\begin{array}{c}7.09 \\
(5.40 ; 8.78)\end{array}$ & $\begin{array}{c}0.15 \\
(-2.25 ; 2.56)\end{array}$ & $\begin{array}{c}0.59 \\
(-1.10 ; 2.28)\end{array}$ & $\begin{array}{c}0.49 \\
(-1.80 ; 2.78)\end{array}$ \\
\hline 16 & $\begin{array}{l}\text { I am able to recognise that the } \\
\text { process of reflective practice } \\
\text { helps to guide my clinical } \\
\text { practice. }\end{array}$ & $\begin{array}{c}8.16 \\
(6.63 ; 9.69)\end{array}$ & $\begin{array}{c}-0.83 \\
(-3.01 ; 1.35)\end{array}$ & $\begin{array}{c}-0.49 \\
(-2.92 ; 1.94)\end{array}$ & $\begin{array}{c}0.61 \\
(-2.67 ; 3.90)\end{array}$ \\
\hline 17 & $\begin{array}{l}\text { I am able to view reflective } \\
\text { practice as an effective use of } \\
\text { my time. }\end{array}$ & $\begin{array}{c}7.06 \\
(4.87 ; 9.25)\end{array}$ & $\begin{array}{c}-1.77 \\
(-4.88 ; 1.33)\end{array}$ & $\begin{array}{c}0.25 \\
(-2.36 ; 2.86)\end{array}$ & $\begin{array}{c}1.46 \\
(-2.04 ; 4.96)\end{array}$ \\
\hline 18 & $\begin{array}{l}\text { I am able to think about my } \\
\text { clinical abilities in a positive } \\
\text { manner after the process of } \\
\text { reflection. }\end{array}$ & $\begin{array}{c}7.57 \\
(5.89 ; 9.26)\end{array}$ & $\begin{array}{c}-1.64 \\
(-4.03 ; 0.75)\end{array}$ & $\begin{array}{c}0.51 \\
(-1.46 ; 2.48)\end{array}$ & $\begin{array}{c}0.80 \\
(-1.96 ; 3.47)\end{array}$ \\
\hline 19 & $\begin{array}{l}\text { I am able to recognise that } \\
\text { participating in reflective } \\
\text { practice group develops my } \\
\text { ability to reflect. }\end{array}$ & $\begin{array}{c}6.88 \\
(4.55 ; 9.20)\end{array}$ & $\begin{array}{c}-1.22 \\
(-4.54 ; 2.10)\end{array}$ & $\begin{array}{c}0.10 \\
(-3.41 ; 3.60)\end{array}$ & $\begin{array}{c}1.11 \\
(-3.68 ; 5.90)\end{array}$ \\
\hline 20 & $\begin{array}{l}\text { I am able to learn by hearing } \\
\text { about my peers' clinical } \\
\text { experiences. }\end{array}$ & $\begin{array}{c}8.03 \\
(6.33 ; 9.72)\end{array}$ & $\begin{array}{c}-0.79 \\
(-3.21 ; 1.64)\end{array}$ & $\begin{array}{c}-0.07 \\
(-2.41 ; 2.28)\end{array}$ & $\begin{array}{c}0.68 \\
(-2.50 ; 3.85)\end{array}$ \\
\hline 21 & $\begin{array}{l}\text { I am able to engage in } \\
\text { discussion within reflective } \\
\text { practice groups. }\end{array}$ & $\begin{array}{c}7.96 \\
(6.36 ; 9.57)\end{array}$ & $\begin{array}{c}0.06 \\
(-2.23 ; 2.36)\end{array}$ & $\begin{array}{c}0.31 \\
(-1.31 ; 1.94)\end{array}$ & $\begin{array}{c}-0.26 \\
(-2.47 ; 1.95)\end{array}$ \\
\hline 22 & $\begin{array}{l}\text { I am able to recognise that } \\
\text { having a facilitator to lead } \\
\text { reflective practice group is } \\
\text { helpful to my learning. }\end{array}$ & $\begin{array}{c}8.07 \\
(6.42 ; 9.72)\end{array}$ & $\begin{array}{c}-0.70 \\
(-3.05 ; 1.66)\end{array}$ & $\begin{array}{c}-0.28 \\
(-2.49 ; 1.93)\end{array}$ & $\begin{array}{c}0.90 \\
(-2.08 ; 3.88)\end{array}$ \\
\hline 23 & $\begin{array}{l}\text { I am able to recognise that } \\
\text { using games/activities in } \\
\text { reflective practice group is } \\
\text { helpful to my learning. }\end{array}$ & $\begin{array}{c}5.53 \\
(3.33 ; 7.73)\end{array}$ & $\begin{array}{c}-0.37 \\
(-3.51 ; 2.77)\end{array}$ & $\begin{array}{c}-1.12 \\
(-4.81 ; 2.58)\end{array}$ & $\begin{array}{c}2.40 \\
(-2.657 .46)\end{array}$ \\
\hline \multirow[t]{2}{*}{24} & $\begin{array}{l}\text { I am able to compare my } \\
\text { clinical situation/ experience } \\
\text { with my peers' experiences. }\end{array}$ & $\begin{array}{c}8.54 \\
(7.34 ; 9.74)\end{array}$ & $\begin{array}{c}-1.22 \\
(-2.92 ; 0.48)\end{array}$ & $\begin{array}{c}-0.39 \\
(-2.20 ; 1.42)\end{array}$ & $\begin{array}{c}1.44 \\
(-1.04 ; 3.91)\end{array}$ \\
\hline & Average & $\begin{array}{c}7.21 \\
(6.15 ; 8.26) \\
\end{array}$ & $\begin{array}{c}-0.54 \\
(-1.97 ; 0.79) \\
\end{array}$ & $\begin{array}{c}0.48 \\
(-0.77 ; 1.74) \\
\end{array}$ & $\begin{array}{c}0.51 \\
(-1.57 ; 2.59) \\
\end{array}$ \\
\hline
\end{tabular}

Comparison of participant perceptions between group conditions. Table 2 also illustrates the pre- and post-intervention effect of experimental practice in comparison to standard practice for student perceptions of reflective practice. This is represented by population estimates of a shift in intercepts of the linear mixed-effects model. Almost all questions show smaller estimated average scores for the experimental condition: however, the effect was not 
large enough to reject any corresponding null hypothesis at a family-wise error level of 0.05 . Therefore was no significant effect for participants in experimental practice condition, as compared to the standard practice condition.

\section{Discussion}

This study examined the perceptions of SLP students' development of reflective practice skills within group settings across two conditions, standard practice and experimental practice. The aims of the study were to determine student perceptions of reflective practice as a learning tool, identify changes in their perceptions over time and compare perceptions of development between students in the experimental condition (structured activities) and the standard practice condition. Pre- and post-intervention comparisons did not detect a significant change in student perceptions of development of reflective practice skills in either condition over time. A between conditions comparison of student perceptions did not detect a significant difference between conditions. The findings are discussed below along with some possible clinical implications for verbal reflective practice groups, the limitations of the current study, and suggestions for future research.

The results of the current study indicated that the SLP students sampled, viewed both reflective practice and specifically verbal reflective practice as a positive addition to their learning, critical thinking and clinical practice. This was indicated by the average estimates of 6.66 to 7.72 out of a possible score of 10 on the VAS indicating positive perceptions of reflective practice as a learning tool at this point in their SLP education. Additionally, students perceived that they were able to learn from and contribute to their peer's learning. This result supports prior studies that have similarly described positive attitudes of students towards group learning opportunities (McGrath \& Higgins, 2006; McKinlay \& Ross, 2008; Schaub de Jong et al., 2009). Students also perceived reflective practice to be a worthwhile use of time, contradicting prior studies that have raised reflective practice as time consuming and possibly resulting in reduced student engagement (Harris 2005; Roche \& Coote, 2008). The positive student response and willingness to engage in reflective practice was also an encouraging finding for those in tertiary education and field supervision who are educating SLP students, as reflective practice is an area of competency that students must develop to be considered ready for the workplace (Speech Pathology Australia, 2011).

A further important finding was that students' perceptions of their reflective practice abilities remained stable over the six-week period spent in reflective practice groups. Students perceived they maintained their perceived skill levels (6.66 to 7.72 out of a possible score of 10). However, these findings contrast with prior studies that have assessed reflective practice skill level and suggested that reflective practice skills, such as linking theory to practice, explaining thought processes, viewing multiple perspectives, and reflecting on performance, do/can develop over time (Cook et al. 2017; Duke \& Appleton, 2000). One possible reason for this finding is that students may have been less experienced at reflecting on or percieving their own skill development accurately compared to past studies that used CEs who were experienced at evaluting student clinical skill abilities (Cook et al. 2017; Duke \& Appleton, 2000; Hill et al., 2012). Perhaps a comparison to their past rating, clinical competency or objective measure of their reflective practice skill level may have better highlighted reflective practice development. 
In contrast to our hypothesis, there was no difference in student perceptions between the experimental practice and standard practice VAS scores. This was unexpected given the body of literature supporting the need for and use of activities and/or structure to engage students in the learning process and maximise reflection (Boud \& Walker, 1998; Gray 2007, Mastergeorge, 2009; McDougall \& Comfort, 2013). This finding may offer some support for the possibility that structured activities and prompts used in the experimental practice condition restrict student creativity of thought during reflection and hinder the process or their perception of the process (Johns, 2013). Thus, students in the experimental practice condition may have felt that by having specific prompts they were required to respond to, their original thoughts and contribution were constrained. As students had no prior experience with reflective practice groups, the format of the discussion component within reflective practice groups itself may have also been a contributing factor to the null finding of student perception between the experimental practice and standard practice conditions. Reflective practice groups in both conditions were run in a format that remained unchanged from week to week. The discussion component was either unstructured (standard practice) or structured (experimental practice). This meant that for those students in the standard practice condition, discussion often flowed in a different way each week and students in this condition appeared to respond in a positive manner to this format. Equally, those students participating in the experimental practice condition may have responded positively to the consistency of the discussion format each week.

Implication for clinical education. The findings of the current study are positive for both students and CEs in the area of verbal reflective practice. Firstly, these data indicate that students view verbal reflective practice groups as a positive addition to their learning experiences. Secondly, utilizing a reflective practice group can be an efficient use of CE time and may even reduce the need for individual supervision sessions in some instances. Thirdly, students do not appear to have a strong preference for either an approach that involves structured discussion with activities, or a standard approach wth student-led discussion. Therefore, CEs may choose whichever approach best meets the needs of a particular group.

Limitations and further research. The findings of current study should be viewed within the context of its limitations. Firstly, a non-validated questionnaire was used due in data collection, which may have influenced the results. Specifically, as multiple questions may have assessed similar areas and response values may have been more heavily weighted by these similar questions. Future studies could examine and verify the validity of a reflective practice questionnaire. Secondly, while gaining a student perspective of reflective practice development was the aim of this study, it is acknowledged that the type and kind of structured activities and prompting questions could be further examined to determine if students find the specific structure useful. This area can also be further enhanced by measuring the student's actual development of reflective practice skills over time across the two conditions. Additionally, future studies could examine the influence of student choice of structured or unstructured reflective practice groups on their perception of the value of reflective practice. Finally, the limited time between the first and final round of the questionnaire being distributed may have contributed to the null result both overtime and between groups. 


\section{Conclusion}

This study demonstrated that students in both conditions perceived reflective practice as a positive learning tool. However, their perceived skill level did not change over time. Students further perceive that they were engaged in the learning process regardless of the facilitation format of their reflective practice groups. In addition, student perception regarding development of their own reflective practice skills did not change over time for students in either a standard practice or experimental practice condition. Finally, this study concludes that SLP students view the verbal reflective practice experience as a positive contribution towards their development of critical thinking and reasoning skills.

\section{Acknowledgements}

The authors would like to thank all speech-language pathology students who participated in this study during the 2015 academic year.

\section{Declaration of interest}

The authors report no conflicts of interest. The authors alone are responsible for the content and writing of the paper.

\section{References}

Bates, D., Maechler, M., Bolker, B., \& Walker, S. (2015). Fitting linear mixed-effects models using lme4. Journal of Statistical Software, 67(1), 1-48.

Baxter, S., \& Gray, C. (2001). The application of student-centred learning approaches to clinical education. International Journal of Language \& Communication Disorders, 36(2), 396-400.

Boud, D., \& Walker, D. (1998). Promoting reflection in professional courses: The challenge of context. Studies in Higher Education, 23(2), 191-206.

Boud, D., Keogh, R., \& Walker, D. (1985). Reflection: turning experience into learning. London: Kogan Page

Brookshire, R. H. (2003). Introduction to neurogenic communication disorders (6th ed.). St. Louis, MO: Mosby Inc.

Bruce, C., Parker, A., \& Herbert, R. (2001). The development of a self-directed and peer-based clinical training programme. International Journal of Language \& Communication Disorders, 36(2), 401-405.

Caty, M., Kinsella, E. A., \& Doyle, P. C. (2015). Reflective practice in speech-language pathology: A scoping review. International Journal of Speech-Language Pathology, 17(4), 1-10.

Clouder, L. (2000). Reflective practice in physiotherapy education: A critical conversation. Studies in Higher Education, 25(2), 211-223.

Cook, K,. Tillard, G,. Wyles, G,. Gerhard, D., Ormond, T. \& McAuliffe, M. (2017). Assessing and developing the written reflective practice skills of speech-language pathology students. International Journal of Speech-Language Pathology, DOI 
10.1080/17549507.2017.1374463

Dubé, V., \& Ducharme, F. (2014). Reflective practice among nurses working in a teaching hospital: An action research with promising benefits for professional development. Journal of Nursing Education and Practice, 4(8), 9-19.

Dubé, V., \& Ducharme, F. (2015). Nursing reflective practice: An empirical literature review. Journal of Nursing Education and Practice, 5(7), 91-99.

Duke, S., \& Appleton, J. (2000). The use of reflection in a palliative care programme: A quantitative study of the development of reflective skills over an academic year. Journal of Advanced Nursing, 32(6), 1557-1568.

Dunfee, H., Rindflesch, A., Driscoll, M., Hollman, J., \& Plack, M. M. (2008). Assessing reflection and higher-order thinking in the clinical setting using electronic discussion threads. Journal of Physical Therapy Education, 22(2), 60-67.

Franks, V., Watts, M., \& Fabricus, J. (1994). Interpersonal learning in groups: An investigation. Journal of Advanced Nursing, 20, 1162-1169.

Freeman, M. (2001). Reflective logs: An aid to clinical teaching and learning. International Journal of Language \& Communication Disorders, 36, 411-416.

Fronek, P., Kendall, M., Ungerer, G., Malt, J., Eugarde, E., \& Geraghty, T. (2009) Towards healthy professional-client relationships: The value of an interprofessional training course. Journal of Interprofessional Care, 23(1), 16-29.

Geller, E., \& Foley, G. M. (2009). Broadening the "ports of entry" for speech language pathologists: A relational and reflective model for clinical supervision. American Journal of Speech-Language Pathology, 18(1), 22-41.

Graham, I. (1995). Reflective practice: Using the action learning group mechanism. Nurse Education Today, 15, 28-32.

Gray, D. E. (2007). Facilitating management learning: Developing critical reflection through reflective tools. Management Learning, 38(5), 495-517.

Haddock, J. (1997). Reflection in groups: contextual and theoretical considerations within nurse education and practice. Nurse Education Today 17, 381-385.

Harris, M. (2005). Is journaling empowering? Students' perceptions of their reflective writing experience. Health SA Gesondheid, 10(2), 47.

Heidar, F., \& Galvin, K. (2002). Action learning groups: can they help students develop their knowledge and skills? Nurse Education in Practice 3, 49-55.

Higgs, J., \& McAllister, L. (2007). Educating clinical educators: Using a model of the experience of being a clinical educator. Medical Teacher, 29(2-3), e51-e57.

Hill, A., Davidson, B., \& Theodoros, D. (2012). Reflections on clinical learning in novice speech-language therapy students. International Journal of Language \& Communication Disorders, 47(4), 413-426.

Johns, C. (1994). A philosophical basis for nursing practice. Oxford: Blackwell Scientific Publications.

Johns, C. (1995). The value of reflective practice for nursing. Journal of Clinical Nursing, 4(1), 23-30.

Johns, C. (2013). Becoming a reflective practitioner. Retrieved from https://ebookcentra.proquest.com

Johnston, G., \& Banks, S. (2000). Interprofessional learning modules at Dalhousie University. The Journal of Health Administration Education, 18(4), 407-427.

Kember, D. (1999). Determining the level of reflective thinking from students' written 
journals using a coding scheme based on the work of mezirow. International Journal of Lifelong Education, 18(1), 18-30.

Kinsella, E. A. (2001). Reflections on reflective practice. Canadian Journal of Occupational Therapy, 68(3), 195-198.

Kinsella, E. A., Caty, M., Ng, S., \& Jenkins, K. (2012). Reflective practice for allied health: theory and applications. In L. English (Ed.), Adult Education and Health (pp. 210226). Canada: Univerity of Toronto Press.

Knowles, M., Holton, E., \& Swanston, R. (2005). The Adult Learner: The Definitive Classic in Adult Education and Human Resource Development. USA: Elsevier.

Lim, P. H, \& Low, C. (2008a) Reflective practice from the perspectives of the bachelor of nursing students: A focus interview. Singapore Nursing Journal, 35(4), 42-48.

Lim, P. H, \& Low, C. (2008b) Reflective practice from the perspectives of the bachelor of nursing students in International Medical University (IMU). Singapore Nursing Journal, 35(3), 5-15.

Mamede, S., \& Schmidt, H. G. (2004). The structure of reflective practice in medicine. Medical Education, 38(12), 1302-1308.

Mastergeorge, A. M. (2009). A tool for assessing engagement in instructional contexts. Seminars in Speech and Language, 30(1), 48-56.

McAllister, S., Lincoln, M., Ferguson, A., \& McAllister, L. (2013, 2nd Ed.). COMPASS® Competency Assessment in speech pathology technical manual. Melbourne, Australia: Speech Pathology Association of Australia.

McAllister, L., \& Lincoln, M. (2004). Clinical education in speech-language pathology. London: Whurr Publishers Ltd.

McDougall, L., \& Comfort, L. (2013). Reflective practice: A way of learning for community development practitioners [Discussion paper]. Calgary, CA: Community Development Learning Initiative.

McGrath, D., \& Higgins, A. (2006). Implementing and evaluating reflective practice group sessions. Nurse Education in Practice, 6(3), 175-181.

McKinlay, L., \& Ross, H. (2008). You and others: Reflective practice for group effectiveness in human services. Toronto, ON: Pearson Canada Ltd.

McVey, J., \& Jones, T. (2012). Assessing the value of facilitated reflective practice groups. Cancer Nursing Practice, 11(8), 32-37.

Meizrow, J. (1990). Fostering critical reflection in adulthood: A guide to transformative and emancipatory learning. San Francisco, CA: Jossey-Bass.

Ng, S., Bartlett., D., \& Lucy, S. D. (2012). Reflection as a window to student development: Insight for faculty, preceptors and mentors. Seminars in Hearing, 33 (02), 147-162.

O'Halloran, R., Hersh, D., Laplante-Lévesque, A., \& Worrall, L. (2010). Personcenteredness, ethics, and stories of risk. Seminars in Speech and Language, 31(2), 081089.

Osterman, K. F., \& Kottkamp, R. B. (1993). Reflective practice for educators: Improving schooling through professional development. Thousand Oaks, CA: Corwin Press.

Plack, M. M., Driscoll, M., Blisset, S., McKenna, R., \& Plack, T. P. (2005). A method for assessing reflective journal writing. Journal of Allied Health, 34 (4), 199-208.

Qualtrics (2017). Qualtrics, Provo, UT, USA. Available from http://www.qualtrics.com

Quinn, F. M. (2000). Reflection and reflective practice. In C. Davies, L. Finlay 
\& A. Bullman (Eds.), Changing practice in health and social care. (pp. 81-90). London: Sage.

Ritz, C., Laursen, P. L., \& Damsgaard, C. T. (2016). Simultaneous inference for multilevel linear mixed models - with an application to a large-scale school meal study. Journal of the Royal Statistical Society, Series C, Applied Statistics, 66(2), 295-311.

Roche, A. \& Coote, S. (2008). Focus group study of student physiotherapists' perceptions of reflection. Medical Education, 42, 1064-1070.

Schaub-de Jong, M. A., Cohen-Schotanus, J., Dekker, H., \& Verkerk, M. (2009). The role of peer meetings for professional development in health science education: A qualitative analysis of reflective essays. Advances in Health Sciences Education, 14(4), 503-513.

Schön, D. A. (1987). Educating the reflective practitioner: Toward a new design for teaching and learning in the professions. San Francisco: Jossey-Bass.

Speech Pathology Australia (2011). Competency based occupational standards. Retrieved from http://www.speechpathologyaustralia.org.au/spaweb/Document_Management/Public/ CBOS.aspx

Stock Whittaker, D. (1985). Using groups to help people. Routledge \& Kegan Paul, London

Teekman, B. (2000). Exploring reflective thinking in nursing practice. Journal of Advanced Nursing, 31(5), 1125-1135.

Wainwright, S. F., Shepard, K. F., Harman, L. B., \& Stephens, J. (2010). Novice and experienced physical therapist clinicians: A comparison of how reflection is used to inform the clinical decision-making process. Physical Therapy, 90(1), 75-88.

Wong, F. K. Y., Kember, D., Chung, L. Y. F., \& Yan, L. (1995). Assessing the level of student reflection from reflective journals. Journal of Advanced Nursing, 22(1), 4857. 


\section{Appendix}

Description of qualitative and quantitative measures used to develop the questionnaire

COMPASS® (McAllister et al., 2013)

Mode: Verbal discussion and visual analogue scale

Description: COMPASS ${ }^{\circledR}$ is a validated assessment used to assess SLP students' overall competency during their Speech-Language Pathology degree (McAllister et al., 2013). It can also be used to structure teaching, and establish goals to further skill development (McAllister et al., 2013). COMPASS ${ }^{\circledR}$ consists of four professional competencies and seven Competency Based Occupational Standards.

Key terminology:

- Reasoning competency elements: The student will "use effective thinking skills to ensure quality speech pathology practice, integrate collaborative and holistic viewpoints into professional reasoning, [and] use sound professional reasoning strategies to assist planning for all aspects of service management" (McAllister et al., 2013 pg 15).

- Learning competency elements: The student will "reflect on performance, structure own learning/professional development, demonstrate an effective attitude to learning [and] is able to change performance" (McAllister et al., 2013, pg 20).

- Life-long learning and reflective practice element: The student will "participate in professional development and continually reflect on practice" (McAllister et al., 2013, pg 36).

Written reflective practice coding schema (Plack et al. 2005)

Mode: Written reflection samples

Description: The Plack et al. (2005) coding schema was developed in line with theories of reflective practice (e.g., Boud et al., 1985; Meizrow, 1990; Schön, 1987) and modified from earlier coding schemes (e.g., Wong et al., 1995). This coding schema assesses a broad range of reflective practice skills (breadth of reflection) and has been used to reliably assess reflective practice skills in the written reflections of physiotherapy (Plack et al., 2005) and speech-language therapy students (Hill et al., 2012).

Key terminology:

Reflective practice breadth elements:

- Return - Describes the experience.

- Attend - Acknowledges and begins to work with feelings (positive or negative).

- Reflection on action - Reflection occurs after the action has been completed.

- Reflection for action - Reflection occurs before being faced with the situation; begins to plan for the future.

- Process - Describes the strategies used or available.

- Reflection in action - Occurs while in the midst of an action; that is, makes on the spot decisions.

- Content - Explores the experience from another perspective.

- Re-evaluates - Reappraises the situation vis-à-vis past experiences.

- Premise - Recognizes and explores own assumptions, values, beliefs and biases. 
Research investigating student perceptions of reflective practice (Lim \& Low, 2008a; 2008b; Harris, 2005; Ng et al. 2012 ; Roche \& Coote 2008)

Modes: Questionnaire, self-evaluation and focus group

Description: Studies completed with nursing and audiology students with a view to gain student perceptions on verbal or written reflective practice participation.

Key terminology:

- Student perceptions of reflective practice: A memory aid, a way to gain feedback, a dedicated time to reflect, increased self-awareness, enjoyment of group discussions, complementing evidenced based practice, self care, developing professional identity and time consuming. 